cesses for the new NHS-to which we hope this article contributes-will help to ensure that the light shines through.

1 Department of Health. Managing the new NHS. London: Department of Health, 1993.

2 Williamson OE. Market and hierarchies. New York: Free Press, 1975

3 Carnaghan R, Braeewell-Milnes B. Testing the market. Competitive tendering for
Aovermment servic

Scott $H$. The east London primary care development project. In: Boyle $S$, ed. London monitor: focusing on London's health services. London: King's Fund, 1994.

5 Osborne D, Gaebler T. Reinventing government. How the entrepreneurial spirit is transforming the public sector in the USA. Reading, MA: Addison-Wesley, 1992.

(Accepted 6 February 1994)

\title{
Managing the NHS market
}

\author{
Chris Ham, Alan Maynard
}

The purpose of the present NHS reforms is to introduce a managed market; developing some of the incentives for greater efficiency that are often found in markets while still being able to regulate proceedings to prevent market failures. If government intervenes too much there will be no incentive to improve efficiency and streamline operations: too little intervention may result in some areas having inadequate health service cover or monopoly powers abusing their position. Effective management of the NHS market requires eight core elements: openness of information, control of labour and capital markets, regulation of mergers and takeovers, arbitrating in disputes, protection of unprofitable functions such as research and development, overseeing national provision of health services, protection of basic principles of the NHS, and handling of closures and redundancy. Management of the market would best be performed by the NHS management executive and health authority purchasers acting within a framework set by politicians.

The key challenge facing ministers in implementing NHS reforms is to strike the right balance between competition and regulation. Although the term internal market is often used to describe the reforms, it would be more accurate to call it a managed market. One reason for preferring this terminology is that competition is not confined to NHS providers but includes providers outside the NHS. Even more important is the fact that it has never been the intention, as some observers have contended, to introduce a free market. Rather, the aim has been to develop some of the incentives that are often found in markets in the structure of the NHS and to regulate the operation of these incentives to avoid the problems of market failure.

\section{Implementing the reforms}

In the early stages of the reforms ministers pursued a policy of gradual and controlled change. The watchwords in 1991 and '92 were "steady state" and "smooth take off," indicating the government's wish for the minimum of turbulence as purchasers and providers took on their new responsibilities. Since then some of the controls imposed from the centre have been relaxed, and this year the secretary of state for health has said that the time has come "to make it happen." In particular, she has emphasised the need for purchasers to act as the engine to drive the reforms and to use their purchasing power to bring about improvements in both health and health services. The effects of the government's policy have been felt particularly in London and the larger conurbations, where the pace of change has been greater than in other parts of the NHS and where the market has already caused casualties.

The example of London is especially instructive. Ministers responded to the problems that arose in

\section{Core elements for management of NHS market}

- Openness of information

- Control of labour and capital markets

- Regulation of mergers and takeovers

- Arbitrating in disputes

- Protection of non-profit making functions

- Overseeing provision of health services

- Protection of basic principles of NHS

- Dealing with closures and redundancies

London not by allowing the market to do its job but by setting up an inquiry under Professor Bernard Tomlinson. As an interim measure, extra funds were also allocated to the Thames regions amounting to over $£ 100 \mathrm{~m}$ in the current year-to make up for the shortfalls in hospitals' budgets caused by changes in contracts. In this way, the signals thrown up by the market were managed with a strategic overview and transitional funding in an attempt to ensure an orderly process of change.

\section{CONTRADICTORY SIGNALS}

As yet unanswered is the question of whether it will be possible to ensure that change is managed efficiently without this blunting the very incentives that are meant to be a stimulus to improve performance. The indications on this point are contradictory. On the one hand, some health authorities are moving contracts more rapidly than anticipated by Tomlinson, thereby making it difficult to implement a strategy for rationalising hospital provision in a planned fashion. On the other hand, ministers have recently intervened in the market in London to prevent Camden and Islington Health Authority from undermining University College London Hospitals by switching services to less expensive providers. The secretary of state for health justified her intervention on the grounds that a managed market required regulation from the centre in particular cases. For his part, Bernard Tomlinson has expressed concern that the government has not intervened sufficiently in the market, both to provide additional resources to smooth the process of transition and to manage the run down of hospitals.

Dangers of intervention-The problem for ministers is that if they do intervene more than has been the case so far they run the risk of weakening the incentives to providers to cut their costs and raise standards. A culture in which providers who are unsuccessful receive political protection and extra funding to balance their budgets would not be conducive to the improvements in efficiency and quality that ministers want. If such a culture were to develop, competition would function only at the margins and the market would be tightly managed to maintain inefficiency. Thus the 
result would be the worst of both worlds: a mixture of old style bureaucratic controls coupled with the additional transaction costs of the market and without the benefits of either approach.

Dangers of competition - Inevitably, competition may run counter to the principles and values of a publicly funded health service. For this reason, it is essential that the structure of the NHS permits the decisions of purchasers and providers to be regulated. For example, if the population in a certain area may not have ready access to necessary hospital facilities intervention will be necessary. Equally, if medical research that is agreed to be worth supporting cannot be funded by purchasers there must be a way of doing this separately from the market allocation of resources. It is essential that competition evolves within a clear and explicit framework of rules to prevent the emergence of anti-competitive behaviour and the exploitation of monopoly power.

\section{Need for proper management}

In view of these issues, market management needs more urgent consideration than it has so far received. Setting up Tomlinson-like inquiries on an ad hoc basis has worked in the short term, but this is not the best way of managing the market on a continuing basis. What is needed is much greater clarity about the functions involved in market management and a debate about where these functions should be located. The present work to implement the government's proposals for the management of the new NHS offers an opportunity for these issues to be debated and for the new management arrangements to incorporate for the first time an effective market management function. As a starting point, we suggest that effective market management requires eight core elements.

THE EIGHT PILLARS OF WISDOM

Openness of information

Purchasers will want to make comparisons between providers before deciding where to place their contracts, and this requires the setting of clinical standards (such as those set out in the effective health care bulletins) and the audit of performance to ensure these standards are met. Pricing behaviour is likely to ignore the rules of the NHS management executive (that price should equal average cost) as it will be to the advantage of purchasers and providers alike to strike confidential deals. As in most markets, prices will bear little relation to opportunity cost, thus making management complex.

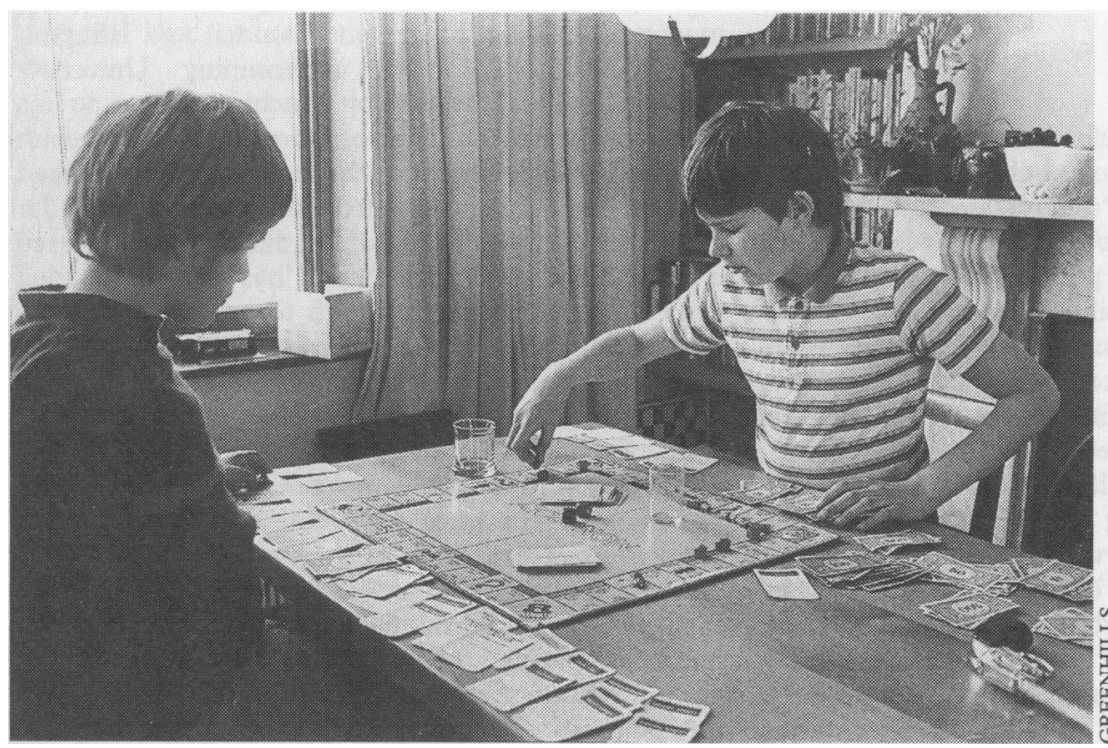

Mergers and takeovers must be controlled to prevent monopolies

\section{Control of labour and capital markets}

The rules for managing labour and capital markets will need to be clearly articulated. The supply of doctors may need to be controlled centrally to ensure that the number of clinicians and general practitioners and the demands they create are regulated. The rewards of doctors and their contracts will have to be revised cautiously and not by ad hoc reform of particular elements of the payment system (such as distinction awards). A capital market, promised in 1989 , will need to be developed to replace the cumbersome, bureaucratic mechanisms of allocation that are presently used. It is difficult to see how this can be achieved without the privatisation of trusts, and if this is indeed the outcome there will need to be safeguards to protect access and equity. There is an acute risk that greater flexibility in the labour and capital markets could substantially inflate costs.

\section{Regulation of mergers and takeovers}

There needs to be an agreed policy for handling mergers and takeovers. In all markets there is a tendency for providers to protect their position and to ensure survival by creating monopolies. At one level this means establishing cartels to manipulate prices and frustrate purchasers in their search for efficiency gains. At another level it leads to a process of concentration in which stronger providers take over those who are weaker and are then able to exploit their power in the market. There are various ways of dealing with these issues, including legislation, regulatory agencies (of the kind found in former public utilities such as gas, electricity, water, and telecommunications), and monopolies and mergers commissions. In the NHS the aim should be to spell out how mergers and takeovers will be regulated and then to decide upon the nature and functions of a regulatory agency similar to those established in other public utilities.

\section{Arbitrating in disputes}

Market management requires the capacity to arbitrate in disputes between purchasers and providers without recourse to the courts. NHS contracts are not legal documents, and it would be a misuse of scarce public funds if health authorities had to sue NHS trusts for failing to fulfil these contracts. In the absence of legal redress an alternative arrangement has to be made for settling disputes and adjudicating in conflicts. As contracting relations mature the need for arbitration is likely to decline, but for the foreseeable future an arbitration agency independent of purchasers and providers is needed.

\section{Protection of non-profit making functions}

There are some functions which cannot be left to the market. Of particular importance is research and development, especially the evaluation of the cost effectiveness of new and existing clinical procedures. It would be unrealistic to expect purchasers operating within constrained budgets to give priority to such activities, and a way must be found to ensure adequate support. In the past regional health authorities have played a major but poorly managed part in funding research and supporting specialised services. The planned abolition of regional health authorities adds urgency to the task of deciding where and how this function should be performed in future.

\section{Overseeing provision of health services}

Market management requires the ability to oversee the interaction of purchasers and providers and to identify gaps in service provision where they occur. This may become even more important if purchasing power is dissipated among an increasing number of general practitioner fundholders. Quite simply, there 


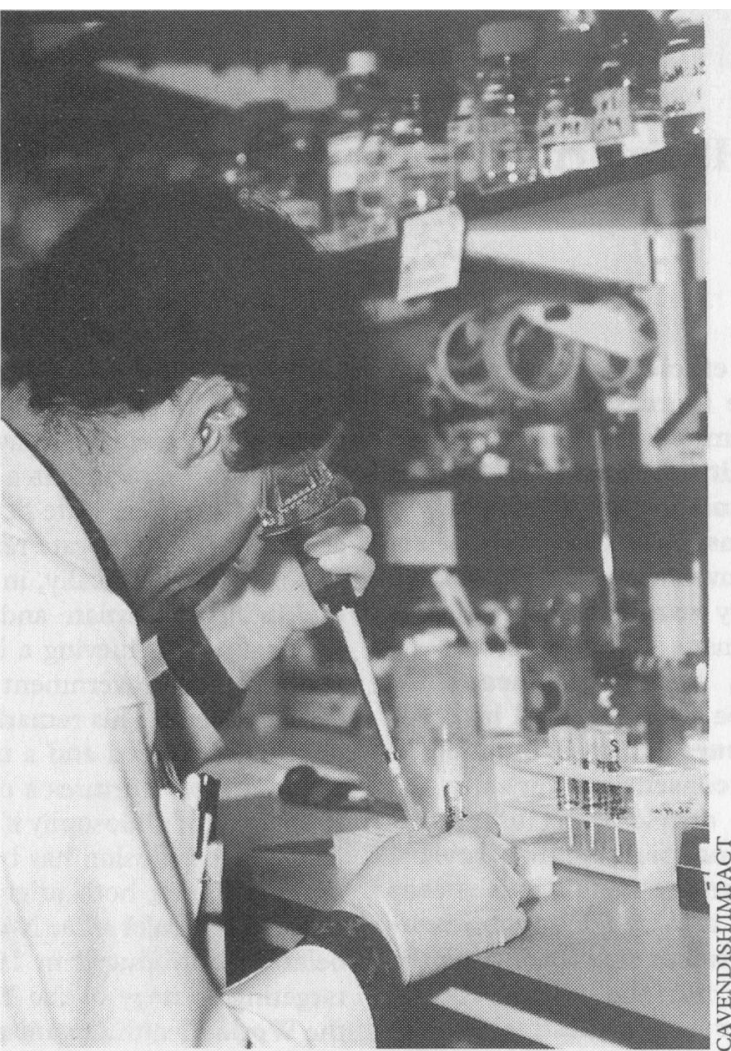

Research and development must be protected in the NHS market must be protected otherwise it will become indistinguishable from the mixed economy of health care in countries such as the United States.

\section{Dealing with closures and redundancies}

Market management also entails the development of exit strategies for coping with providers who compete unsuccessfully in the NHS market. As recently shown, closing hospitals is both complex and costly, and a way has to be found of easing the process of transition and redeploying displaced staff and expertise. Essential elements in this process include short term provision of extra funding and establishing rules for redundancy and relocation of staff and services. In this respect the experience of the London Implementation Group may be useful to the rest of the NHS.

\section{Who should manage the market?}

These eight elements constitute the core of market management. The question then arises as to who should carry them out? District health authorities have a role to play, acting either singly or in combination. They have already demonstrated their capability in many parts of the country by taking the initiative to review the pattern of service provision, and this function will assume greater importance as the market evolves. In addition, health authority purchasers are well placed to plan the rationalisation of services and to work with providers and other interests to ensure that changes are introduced smoothly.

The NHS management executive also has a contri-

is no guarantee that the sum of multiple purchasing decisions will add up to an appropriate pattern of service provision. In view of this it must be possible to identify areas where access to care is adversely affected and to intervene if appropriate. The obverse is the need to avoid unnecessary duplication of services, particularly in relation to those services where a degree of concentration and specialisation is necessary. In this case market management requires the establishment of rules setting out the minimum requirements expected of providers and the conditions that have to be met to establish fitness to provide specialist care.

\section{Protection of basic principles of the NHS}

The founding values and principles of the NHS must not be compromised by competition. As the market develops there is a risk that equity and access will suffer in the pursuit of efficiency and responsiveness to service users. While ministers may be willing to accept a greater degree of inequity and poorer access to services in certain circumstances in return for lower costs and higher quality, to go too far in this direction would be to undermine the whole purpose of a publicly funded health service. The core values of the NHS bution to make and could become the market regulator ("OFHEALTH"). The rules which guide the operation of the market are best set nationally to ensure "a level playing field" in all parts of the NHS. The management executive has set inefficient rules in some cases (such as pricing) and no rules in others (such as capital formation). It needs to develop an effective and mutually reinforcing system of rules to ensure that incentives to purchasers and providers increase the efficiency of resource allocation.

Ultimately, however, it is the strong and continuing political influence in health care which makes the NHS a special case. Ministers carry responsibility for everything that is done in the NHS, and they will always want to retain a close interest in its development. If hospitals have to close, especially famous teaching hospitals, ministers must take this decision and ensure that it is appropriate in the circumstances. While they may be tempted to delegate this task to a semiindependent agency, this can never happen while parliamentary accountability still obtains. For this reason, market management is best performed by the management executive and health authority purchasers operating within a framework set by politicians.

\section{UNUSUAL PROBLEMS}

\section{A macabre question of remuneration}

For some years I have played a game with my staff to identify "The problem of the year," "The problem of the decade," etc. I had always thought that some of our winners were real humdingers until I read the following in the $B M F$ of 10 June 1893 (p 1251), under the heading Queries:

"Member made a postmortem examination on two murdered bodies, and gave evidence touching each death at the inquest. Further and most extensive examination was applied for and granted, as the case rested on medical evidence. Both bodies were exhumed, and placed, at the request of the Authorities, in 'Member's' private house, as the only available or suitable place for examination, and entrusted to his care. An expert was called in, and an assistant. The bodies remained in the house, one for four days and the other eight days. The examination was most exhaustive, occupying eight days. The premises became intolerable; servants gave notice and left; family went away; 'Member' boarded at hotel; friends and patients alike absented themselves; expenses arose for instruments and utensils for macerating, boiling, straining, sifting, and preserving tissues, with disinfecting and limewashing the house afterwards."

The question asked by the correspondent to the $B M \mathcal{F}$ was, "Irrespective of coroner's fees, or Assizes, what remuneration should the government grant for the superintendence and conduct of such an investigation in a private house?"

The $B M Y$ found the circumstances so exceptional that it was unable to advise the correspondent.-Submitted by ROBERT TATTERSALI, professor of clinical diabetes, Nottingham 